\title{
DETERMINANTES DA OFERTA DE EXPORTAÇÃO DE PAPEL NO BRASIL
}

DETERMINANTS OF THE SUPLLAY IN EXPORTATION OF THE PAPERS IN BRAZIL

\author{
Rosana Queiroz Santos ${ }^{1}$ \\ Naisy Silva Soares ${ }^{2}$ \\ Eliane Pinheiro de Sousa ${ }^{3}$
}

\section{RESUMO}

O segmento brasileiro de celulose e papel no Brasil possui uma posição de destaque no cenário nacional e internacional, contribuindo para a geração de empregos, impostos e divisas. O Brasil é um dos maiores exportadores mundiais de celulose. Porém, as exportações nacionais de papel não são representativas como a de celulose. O Brasil foi o décimo quarto exportador mundial de papel, em 2014. Objetivou-se analisar a oferta de exportação de papel no Brasil, utilizando o método de Autorregressão Vetorial com Correção de Erros - VEC. Os resultados mostram que existe uma forte dependência das exportações do papel brasileiro em relação às variações na produção nacional de papel, no consumo, preço interno e taxa de câmbio.

Palavras-chave: Modelo VEC. Análise de sensibilidade. Setor Florestal

\begin{abstract}
The Brazilian pulp and paper segment in Brazil has a prominent position in the national and international scene, contributing to job creation, taxes and currency. Brazil is one of the largest exporters of pulp. However, national paper exports are not representative as cellulose. Brazil was the fourteenth exporter of paper in 2014. The main objective of this study was to analyze the paper export supply in Brazil, using the method of Vector autoregression with Error Correction - VEC. The results show that there is a strong dependence on exports of Brazil's paper in relation to changes in the national paper production, consumption, domestic price and exchange rate.

\footnotetext{
${ }^{1}$ Graduada em Economia pela Universidade Estadual de Santa Cruz (UESC). Especialista em Elaboração e Gestão de Projetos Sociais pela União Metropolitana de Educação e Cultura (UNIME). Mestre em Economia Regional pela Universidade Estadual de Santa Cruz (UESC). E-mail: rqsa13@gmail.com

${ }^{2}$ Graduada em Economia pela Universidade Federal de Viçosa (UFV). Mestre e Doutora em Ciências Ambientais pela Universidade Federal de Viçosa (UFV). Professora da Universidade Estadual de Santa Cruz (UESC). E-mail: naisysilva@yahoo.com.br

${ }^{3}$ Graduada em Economia pela Universidade Federal do Ceará (UFC). Mestre em Economia Rural pela Universidade Federal do Ceará (UFC). Doutora em Economia Aplicada pela Universidade Federal de Viçosa (UFV). Pós-doutora pela Universidade de São Paulo (USP). Professora da Universidade Regional do Cariri (URCA). E-mail: pinheiroeliane@ hotmail.com
} 
Keywords: Model VEC. Sensitivity analysis. Forest Sector

JEL: B23, L73

\section{Introdução}

O segmento brasileiro de celulose e papel no Brasil possui uma posição de destaque no cenário nacional e internacional, contribuindo para a geração de empregos, impostos e divisas. O Brasil é um dos maiores exportadores mundiais de celulose. Porém, as exportações nacionais de papel não são representativas como a de celulose.

Em 2012, o Brasil ocupou o quarto lugar entre os maiores produtores mundiais de celulose e a nona posição entre os países produtores de papel (ASSOCIAÇÃO BRASILEIRA DE CELULOSE E PAPEL - BRACELPA, 2014). Com relação ao mercado internacional, em 2012, o Brasil foi o maior exportador mundial de celulose de fibra curta derivada do eucalipto e o quarto exportador mundial de celulose de todos os tipos. O país foi o décimo quarto exportador mundial de papel, naquele ano (FAO, 2013).

O segmento de celulose e papel começou se destacar na economia brasileira na década de 1950, com o desenvolvimento de uma tecnologia para produção de celulose de fibra curta (GOMIDE, 1988; SOARES et al, 2011).

Além disso, o Estado assumiu um relevante papel de indutor da consolidação do segmento de celulose e papel nacional.

As principais políticas públicas que impulsionaram o segmento de celulose e papel no Brasil foram: Plano Especial de Obras Públicas e Reaparelhamento da Defesa Vargas; Plano de Metas no governo Juscelino Kubitschek; Primeiro Programa Nacional de Papel e Celulose (I PNPC) e Segundo Programa Nacional de Papel e Celulose (II PNPC) no governo Geisel; política de incentivos fiscais de 1966 (Lei 5.106); fixação pelo BNDES, de níveis mínimos de escala de produção; e fixação pelo Conselho de Desenvolvimento Econômico (CDE) de novos níveis mínimos de escala de produção (SOTO, 1992; FURTADO, 2007; BENEVIDES, 2003; ZAEYEN, 1986).

O destaque do Brasil no mercado mundial de papel e celulose também pode ser explicado pela produtividade das florestas nacionais, tecnologia avançada, mão de obra 
qualificada, solo e clima favoráveis para a produção de eucalipto, qualidade do produto nacional e ciclo curto de produção das florestas nacionais (BRACELPA, 2014).

Contudo, evidencia-se que, mesmo diante de uma conjuntura setorial favorável, o Brasil ainda importa papel prejudicando o saldo da balança comercial, a geração de emprego, renda e impostos no país.

Em 2013, o país importou 1,3 milhões de toneladas de papel mesmo a produção nacional conseguindo suprir a demanda doméstica. A produção nacional foi de 10,4 milhões de toneladas e o consumo aparente de 9,8 milhões de toneladas (BRACELPA, 2013). Isso pode ser explicado pela fraude no mercado de papel imune, ou seja, papel isento de tributação (como imposto de importação, IPI, PIS e Cofins e ICMS) quando usado para viabilizar o acesso a informação, estimular o conhecimento e a leitura, isto é, para confecção de livros e jornais, entre outros. Porém, desde 2008, a Bracelpa negociou com o governo federal uma solução para esse problema, que vem prejudicando a concorrência no mercado interno.

O primeiro passo no sentido de avançar no controle das operações com papel imune foi dado em 04/06/2009, por meio da publicação da Lei $\mathrm{n}^{\circ} 11.945$, que traz, nos artigos $1^{\circ} \mathrm{e}$ $2^{\circ}$, dispositivos que estabelecem maior controle sobre as operações com papel imune e, principalmente, mais rigorosas penalidades nos casos de desvio de finalidade. De forma a regulamentar esses dispositivos, a Receita Federal do Brasil publicou em 08/12/2009, a Instrução Normativa $n^{\circ}$ 976, estabelecendo novos mecanismos de obtenção do registro especial e a exigência de recadastramento de fabricantes, distribuidores, importadores, empresas jornalísticas, editores e gráficas, que utilizam papel destinado à impressão de livros, jornais e periódicos, amparados pela imunidade tributária. Além disso, trouxe novas obrigações acessórias para esses agentes de mercado, que facilitarão o monitoramento fiscal das referidas operações (BRACELPA, 2014).

Contudo, outros fatores também influenciam as exportações brasileiras de papel, tais como: preço, taxa de câmbio, quantidade produzida internamente, área reflorestada com eucalipto, entre outras variáveis econômicas (BRACELPA, 2013a).

Tendo em vista a importância do segmento para economia brasileira, faz-se necessário estimular as exportações brasileiras de papel e reduzir as importações do produto. 
Em 2013, por exemplo, o segmento brasileiro de celulose e papel contava com 220 empresas com atividade em 540 municípios localizados em 18 estados, 2,2 milhões de hectares de florestas plantadas para fins industriais, 2,9 milhões de hectares de florestas preservadas, 2,7 milhões de hectares de área florestal total certificada. Em 2012, o segmento apresentou saldo comercial de US\$ 4,7 bilhões, foi responsável pelo pagamento de $\mathrm{R} \$ 3,5$ bilhões em impostos e gerou cerca de 128 mil empregos diretos (indústria 79 mil, florestas 51 mil) e 640 mil empregos indiretos (BRACELPA, 2013).

Nesse contexto, a análise da oferta de exportação de papel pode contribuir para definição de estratégias direcionadas à dinamização do mercado, formulação de políticas públicas para desenvolvimento do segmento e redução das importações de papel. Pode, ainda, auxiliar os agentes ligados ao setor na tomada de decisões sobre produção e comercialização.

Deste modo, o presente trabalho objetivou analisar a oferta de exportação do papel no Brasil. Especificamente, pretende-se analisar o comportamento da oferta de exportação de papel no Brasil e mensurar a sensibilidade da oferta de exportação brasileira de papel em relação a variações no preço de exportação, preço interno, taxa de câmbio, quantidade produzida internamente e consumo aparente.

\section{MATERIAL E MÉTODO}

\subsection{Modelo Teórico}

A função de oferta de exportação é composta por uma vasta combinação de variáveis explicativas potenciais, dada a multiplicidade de fatores que podem afetar a capacidade, bem como a disposição dos produtores de determinado país em produzir e exportar seus produtos.

A capacidade produtiva do setor exportador constitui relevante condicionante das quantidades ofertadas por um país. Desse modo, é provável que um índice apropriado de capacidade produtiva, como a produção interna, seja capaz de explicar parcela significativa da evolução da oferta de exportações, principalmente no que tange ao seu comportamento tendencial. 
A quantidade exportada de um produto depende da diferença entre a produção doméstica e o consumo doméstico do produto. Assim, pode-se inferir que as variáveis que afetam a oferta (S) e a demanda interna (D), influenciam a oferta de exportação, tais como: preço doméstico $(\mathrm{Pd})$; preço de exportação $(\mathrm{Px})$; fatores deslocadores da oferta $(\mathrm{W})$; fatores deslocadores da demanda (Y). Assim, as variáveis escolhidas como determinantes da oferta de exportação de papel no Brasil (Ex) foram: oferta doméstica (Prod), consumo aparente doméstico (Cons), preço interno (Pi), preço de exportação (Px) e taxa de câmbio efetiva real (TC) (KRUGMAN e OBSTFELD, 2005).

Em diversos trabalhos realizados são identificadas diversas variáveis que afetam a oferta de exportação de produtos agropecuários e florestais. Barros et al. (2002) e Alves e Bacchi (2004) consideraram que os fatores determinantes para as exportações eram o preço interno e externo dos bens em consideração, a renda interna e a taxa de câmbio.

Contudo, procedeu-se à seleção de um conjunto de variáveis que, em conformidade com a discussão teórica prévia, pudessem contribuir para explicar a evolução das exportações brasileiras de papel. Sendo assim, influenciada também pela disponibilidade dos dados, as variáveis endógenas escolhidas como determinantes da oferta de exportação de papel no Brasil (Ex) foram: oferta doméstica (Prod), consumo aparente doméstico (Cons), preço interno (Pi), preço de exportação (Px) e taxa de câmbio efetiva real (TC).

Por outro, espera-se que os sinais dos coeficientes de preço interno e do consumo aparente interno sejam negativos, ou seja, que exprimam uma relação inversa com a oferta de exportação de papel. Isso se justifica, pois um aumento no consumo aparente interno conduziria a aumento no consumo de produtos internos, levando a uma queda na disponibilidade de produtos para exportação. Em relação ao preço interno, essa relação negativa poderia ser decorrente do fato de o equilíbrio no mercado interno sinalizar escassez ou não do produto, isto é, preço elevado sinaliza escassez e, portanto, menor exportação (SILVA; et al, 2011).

Se o modelo for expresso em logaritmo, os coeficientes estimados representam as elasticidades e amenizam-se os problemas associados à variância não constante dos erros, quando existirem (ALVES e BACCHI, 2004). 


\subsection{Modelo Analítico}

O instrumental utilizado na pesquisa foi o método de Autorregressão Vetorial com Correção de Erros - VEC, cujos passos são descritos a seguir:

Inicialmente, realiza-se a análise da integração das séries utilizadas.

A ordem de integração das séries utilizadas foi definida, por meio do teste de raiz unitária de Dickey-Fuller Aumentado (ADF), (equações (1) a (3) (ENDERS, 1995):

- Modelo I: sem constante e sem tendência: $\Delta X_{t}=\delta X_{t-1}+\sum_{i=1}^{m} \delta_{i} \Delta X_{t-i}+u_{t}$

- Modelo II: com constante e sem tendência: $\Delta X_{t}=\beta_{1}+\delta X_{t-1}+\sum_{i=1}^{m} \delta_{i} \Delta X_{t-i}+u_{t}$

- Modelo III: com constante e com tendência: $\Delta X_{t}=\beta_{1}+\beta_{2} t+\delta X_{t-1}+\sum_{i=1}^{m} \delta_{i} \Delta X_{t-i}+u_{t}$ (3)

O procedimento utilizado para testar a autocorrelação foi o teste de Johansen (1991), que parte do modelo autorregressivo vetorial (VAR) (equação 4):

$Y_{t}=\theta_{1} Y_{t-1}+\theta_{2} Y_{t-2}+\theta_{3} Y_{t-3}+\ldots \ldots+\theta_{p} Y_{t-p}+B X_{t}+\varepsilon_{t}$

em que $\mathrm{Y}_{\mathrm{t}}$ é um vetor $\mathrm{p}$ x 1 de variáveis $\mathrm{I}(1) ; \boldsymbol{\theta}_{t}$ são matrizes de parâmetros k x k e $\varepsilon_{t}$ é um vetor k-dimensional de termos ruído branco.

Após a determinação do número de defasagens adequado para o modelo VAR, procedeu-se à escolha do modelo de estimação (E-VIEWS, 2004) e para identificar o número de vetores de cointegração, sugere-se o teste do traço (equação 5) e do máximo autovalor (equação 6) (ENDERS, 1995).

$$
\lambda_{\text {trace }}(r)=-T \sum_{i=r+1}^{n} \ln \left(1-\hat{\lambda}_{i}\right)
$$

em que: $\hat{\lambda}_{i}$ são os valores estimados das raízes características obtidos da matriz $\Pi$ e $T$ é o número de observações.

$$
\lambda_{t \max }(r, r+1)=-T \ln \left(1-\hat{\lambda_{r+1}}\right)
$$

$\mathrm{O}$ teste do traço assume como hipótese nula a existência de $\mathrm{r}^{*}$ vetores de cointegração contra a hipótese alternativa de $r>r^{*}$ vetores. A ideia desse teste é buscar o número máximo de vetores de cointegração. O segundo teste é o de máximo autovalor que busca verificar o número exato de vetores de cointegração. A hipótese nula é de que 
existem $\mathrm{r}^{*}$ vetores de cointegração, contra a hipótese alternativa de que existem $\mathrm{r}^{*}+1$ vetores de cointegração. Em ambos os testes, ao se rejeitar a hipótese nula significa que há pelo menos um vetor de cointegração.

Então, parte-se para a estimação do VEC (equação 7) (NOGUEIRA et al, 2005).

$$
\Delta Y_{t}=\Gamma_{1} \Delta Y_{t-1}+\Gamma_{2} \Delta Y_{t-2}+\ldots \ldots .+\Gamma_{p-1} \Delta Y_{t-(p-1)}+\alpha \beta^{\prime} Y_{t-1}+\varepsilon_{t}
$$

em que: $\beta^{\prime} Y_{t-1}=$ relações de cointegração que definem a trajetória de longo prazo entre as variáveis; $\alpha=$ matriz dos coeficientes de ajustamento para o equilíbrio de longo prazo; e $\Gamma_{i}=$ matriz de coeficientes que definem a dinâmica de curto prazo.

Estabelecido o modelo VEC, é possível avaliar a decomposição da variância e a função de impulso-resposta. A decomposição da variância permite separar a variância dos erros de previsão, para cada variável, em componentes que podem ser atribuídos a ela própria e individualmente às demais variáveis endógenas; e a função de impulso-resposta delineia o comportamento das séries incluídas no modelo VAR em resposta a choques ou mudanças provocadas por variáveis residuais (BUENO, 2008).

\subsection{Fontes de dados}

Utilizaram-se dados de séries temporais mensais, de janeiro de 2000 a agosto de 2013. Não se trabalhou com um período maior em decorrência da indisponibilidade de dados e por entender que o período em questão é representativo, visto que se considera os efeitos da abertura comercial no país, bem como os planos de estabilização.

Os dados utilizados no trabalho são do Ministério do Desenvolvimento, Indústria e Comércio (MDIC), Centro de Estudos Avançados em Economia Aplicada (CEPEA), Instituto de Pesquisa em Economia Aplicada (IPEA), BRACELPA (MDIC, 2014; CEPEA, 2014; BRACELPA, 2014 e IPEA, 2014).

\section{RESULTADOS E DISCUSSÃO}

\subsection{Análise da Oferta de Exportação de Papel no Brasil}

O comportamento das exportações de papel do Brasil no período que se estende de 1990 a 2013 é esboçado pela série mensal da figura 10. 
Figura 1 - Evolução da exportação de papel do Brasil - 1990 a 2013

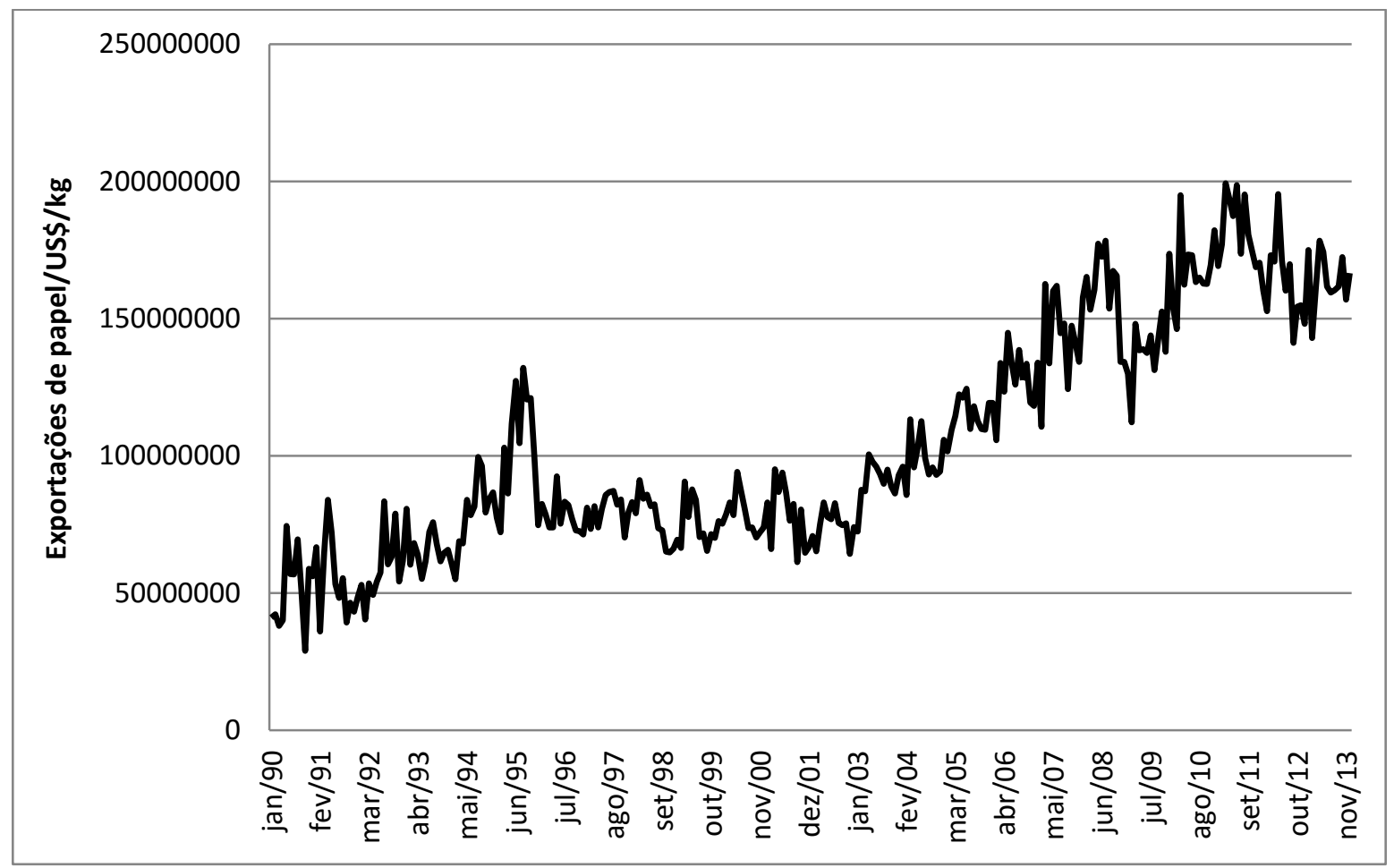

Fonte: MDIC

Observa-se que os montantes das exportações (em US\$ por $\mathrm{kg}$ ) no período analisado apresenta comportamento tendência crescentes positiva. Os fatores que contribuíram para esse crescimento foram a boa receptividade do papel brasileiro no exterior, bem como pelo crescimento das exportações nacionais para o Mercosul e Estados Unidos, crescimento do comércio mundial e da competitividade brasileira no comércio internacional de papeis, conforme observaram Carvalho et al (2010).

A competitividade brasileira no mercado internacional de papel pode ser explicada por meio de alguns aspectos, entre os quais se podem mencionar as políticas do BNDES que vem financiando o segmento de papel e celulose desde a década de 1960. Na década de 1990 a parceria do BNDES com o segmento de celulose e papel elevou seu grau de maturação e o Banco adotou políticas positivas de estímulo ao crescimento da produção e à adoção de práticas empresariais compatíveis com as exigências sociais e mercadológicas. Recentemente, o BNDES tem promovido políticas de inovação financeira e de 
desenvolvimento de estruturas que permitem ao segmento enfrentar a competição internacional (JUVENAL e MATTOS, 2002).

O governo tem investido no aumento das exportações desde 1995, o que possibilitou melhores condições para o setor, tais como: aperfeiçoamento dos mecanismos de financiamento, como o Programa de Financiamento às Exportações - PROEX e o FINAMEX; isenção do Imposto Sobre Circulação de Mercado rias e Serviços - ICMS na exportação de produtos primários e semielaborados; criação do seguro de crédito à exportação; redução do "custo Brasil”, principalmente pelo processo de modernização dos portos; e criação da Agência de Promoção de Exportação - APEX (CAMEX, 1999).

O setor florestal brasileiro tem a seu dispor linhas de crédito para pequenos projetos florestais que são operacionalizados por bancos públicos federais através da concessão por parte do Ministério da Agricultura, Pecuária e Abastecimento (MAPA) e pelo Ministério do Desenvolvimento Agrário (MDA). Estes programas de financiamento visam prioritariamente o desenvolvimento de atividades relacionadas ao setor florestal por meio da operacionalização da implantação florestal (ABRAF, 2009).

Outro fator que também é relevante para explicar a competitividade brasileira é o rápido crescimento das plantações florestais e o baixo custo de produção florestal no país. Entretanto, a competitividade brasileira não é maior devido aos elevados custos do capital e dos portos, assim como carga tributária. A produção de papel é mais desenvolvida em outros países, pois há maiores incentivos governamentais como financiamento com abundância de recursos a juros subsidiados, análises de mercado potenciais, coleta de dados e divulgação para facilitar pesquisas sobre o setor (FAE BUSINESS, 2001; CARVALHO et al, 2010).

\subsection{Estimação da Função de Oferta de Exportação}

Nesta seção, são apresentados os resultados do teste de Dickey-Fuller Aumentado (ADF) nas séries analisadas (Tabela 1). 
Tabela 1 - Valores calculados de ADF, para as variáveis do modelo de oferta de exportação brasileira de papel

\begin{tabular}{ccccc}
\hline Modelo & Variáveis & Modelo I & Modelo II & Modelo III \\
\hline \multirow{5}{*}{ Em nível } & Ex & $-4,00$ & $-2,64$ & $-0,03$ \\
& Prod & $-2,30$ & $-2,50$ & $-1,79$ \\
& Cons & $-3,22$ & $-2,97$ & $-1,08$ \\
& $\mathrm{Pi}$ & $-2,05$ & $-2,66$ & 0,78 \\
& $\mathrm{Px}$ & $-2,18$ & $-0,72$ & 0,79 \\
& $\mathrm{TC}$ & $-1,52$ & $-1,73$ & 0,19 \\
\hline \multirow{5}{*}{ diferença } & Ex & $-23,30$ & $-23,36$ & $-23,42$ \\
& Prod & $-23,42$ & $-23,31$ & $-22,92$ \\
& Cons & $-23,01$ & $-23,06$ & $-23,15$ \\
& Pi & $-13,67$ & $-13,18$ & $-13,10$ \\
& Px & $-17,71$ & $-17,74$ & $-17,72$ \\
& TC & $-8,70$ & $-8,67$ & $-8,67$ \\
\hline
\end{tabular}

Fonte: Dados da pesquisa. Nota: Valores críticos em nível de 1\%. Valores calculados de ADF em nível de $1 \%:-4,01 ;-3,47 ;-2,57$ para os modelos com constante e com tendência, sem constante e com tendência e sem constante e sem tendência, respectivamente.

Os resultados da Tabela 1 sinalizam que as séries não são estacionárias em nível, tendo em vista que os valores calculados são menores em módulo que seus valores críticos em todos os modelos analisados. Mas, são estacionárias na primeira diferença.

Uma vez que as séries possuem a mesma ordem de integração, elas podem ser cointegradas

Assim, buscou-se determinar qual o número de defasagens a ser utilizado na estimação do modelo VAR. Tendo como base os critérios de informação de Akaike, Hannan-Quin e Schwarz, optou-se por seguir a indicação desse último que, segundo Enders (1995), consiste no mais parcimonioso. Dessa forma, considerou-se o modelo com uma defasagem. (Tabela 2). 
Tabela 2 - Número de defasagens do Modelo VAR

\begin{tabular}{cccccc}
\hline Lag & LogL & LR $^{1}$ & Akaike & Schwarz & Hannan-Quin \\
\hline 0 & 1117.286 & NA & -15.32808 & -15.20491 & -15.27803 \\
1 & 1237.445 & 228.7167 & $-16.48890^{*}$ & $-15.62667^{*}$ & $-16.13855^{*}$ \\
2 & 1266.466 & 52.83748 & -16.39263 & -14.79135 & -15.74198 \\
3 & 1288.372 & 38.07070 & -16.19823 & -13.85790 & -15.24727 \\
4 & 1314.913 & 43.92993 & -16.06776 & -12.98838 & -14.81650 \\
5 & 1352.524 & 59.14083 & -16.08999 & -12.27156 & -14.53843 \\
6 & 1378.342 & 38.45969 & -15.94954 & -11.39206 & -14.09768 \\
7 & 1400.929 & 31.77717 & -15.76453 & -10.46800 & -13.61237 \\
8 & 1441.318 & $53.48064^{*}$ & -15.82507 & -9.789486 & -13.37261 \\
\hline
\end{tabular}

Fonte: Dados da pesquisa. *Número de defasagens. ${ }^{1}$ Razão de verossimilhança

Os resultantes do teste de cointegração, mostraram a existência de seis vetores cointegração, ou seja, as variáveis mantêm relações de equilíbrio de longo prazo (Tabela 3).

Tabela 3 - Resultados dos testes de cointegração de Johansen

\begin{tabular}{ccccc}
\hline $\begin{array}{c}\text { Hipótese nula } \\
\left(\mathrm{H}_{0}\right)\end{array}$ & $\lambda_{\text {traço }}$ & $\begin{array}{c}0.05 \\
\text { Valor Crítico }\end{array}$ & $\lambda_{\max }$ & $\begin{array}{c}0.05 \\
\text { Valor Crítico }\end{array}$ \\
\hline $\mathrm{r}=0 *$ & 519.1197 & 103.8473 & 137.8894 & 40.95680 \\
$\mathrm{r} \leq 1 *$ & 381.2303 & 76.97277 & 130.9749 & 34.80587 \\
$\mathrm{r} \leq 2 *$ & 250.2553 & 54.07904 & 91.94786 & 28.58808 \\
$\mathrm{r} \leq 3 *$ & 158.3075 & 35.19275 & 80.97322 & 22.29962 \\
$\mathrm{r} \leq 4 *$ & 77.33423 & 20.26184 & 43.45708 & 15.89210 \\
$\mathrm{r} \leq 5 *$ & 33.87715 & 9.164546 & 33.87715 & 9.164546 \\
\hline
\end{tabular}

Fonte: Dados da pesquisa. * indica rejeição da hipótese a 5\% de significância.

A tabela 4 apresenta o vetor de cointegração que apresentou melhor ajuste aos dados. A normalização foi efetuada considerando-se o valor do coeficiente da variável quantidade exportada de papel pelo Brasil assumindo valor um. 
Tabela 4 - Estimativas do Modelo de Correção de Erros (VEC)

\begin{tabular}{lccc}
\hline Variável explicativa & Coeficiente & Desvio-Padrão & Estatística $t$ \\
\hline Exportação de papel (Ex) & 1.000000 & & \\
Produção de papel (Prod) & 1.965483 & 2.06215 & 0.95312 \\
Consumo de papel (Cons) & -1.204970 & 0.17291 & -6.96871 \\
Preço interno do papel (Pi) & -4.540290 & 1.55970 & -2.91100 \\
Taxa de câmbio (TC) & 1.596653 & 0.76658 & 2.08284 \\
Preço de exportação do papel (PX) & -7.099393 & 1.22127 & -5.81315 \\
Constante & 0.018848 & 0.01636 & 1.15221 \\
\hline
\end{tabular}

Fonte: Dados da pesquisa.

Os resultados dos coeficientes do modelo ajustado apresentaram sinais esperados, exceto o do preço de exportação de papel (Tabela 4).

Constatou-se que um aumento de $1 \%$ na produção de papel, acarreta um aumento de $1,96 \%$ nas exportações nacionais do produto. Entretanto, este coeficiente apresentou-se não significativa para explicar a oferta de exportação de papel no Brasil o que pode está relacionado com outros fatores estarem impactando mais as exportações de papel do país como taxa de câmbio, preço, qualidade do produto, tecnologia e competitividade.

Além disso, como no período analisado ocorreu crescimento da economia brasileira, houve aumento do consumo de livros, revistas e jornais no país, aumentando o consumo de papel internamente. Deste modo, quando a produção aumenta, o principal destino do papel pode ser o mercado doméstico. O que realmente foi observado no período analisado. Isso pode está explicando o fato de o aumento da produção de papel não ter sido significativo para explicar as exportações desse produto.

Um acréscimo de $1 \%$ no consumo nacional de papel leva a uma redução de $1,2 \%$, na oferta de exportação de papel do país. Com isso, pode-se inferir que o crescimento da economia brasileira contribuiu consideravelmente para redução das exportações nacionais, uma vez que proporciona maior demanda por livros, revistas e jornais no país.

Um aumento de $1 \%$ no preço interno do papel reduz $4,5 \%$ as exportações brasileiras de papel. Assim, se o preço interno do papel aumenta, as empresas vão optar por vender sua produção internamente. Esses resultados indicam uma oferta de exportação de papel preço- 
elástica, contrário ao observado em outros estudos que utilizaram modelos univariados para analisar a oferta brasileira de exportação de papel como o de Silva et al (1998).

Sobre a taxa de câmbio, verificou-se que uma desvalorização cambial de $1 \%$, aumenta as exportações nacionais em 1,59\%. Assim, conforme observaram Soares et al (2010), a adoção de uma taxa de câmbio que valorize a moeda nacional pode apresentar consequências danosas para o segmento nacional de celulose e papel no país.

Segundo Silva e Carvalho (1995), as variações na taxa de câmbio têm impacto expressivo sobre a competitividade externa do produto exportado. No caso específico o segmento de celulose e do papel, variações no câmbio podem somar-se aos efeitos dos incentivos às exportações e à produção de outros países, trazendo implicações sobre a competitividade externa da celulose e do papel brasileiro.

O segmento de celulose e papel depende a implementação de medidas que propiciem a melhoria da paridade das moedas, eliminando a valorização excessiva do real frente ao dólar, que tem afetado o desempenho das exportações das empresas em relação a seus principais concorrentes internacionais. Esta medida dará melhor condição para expansão e otimização de fábricas existentes e para construção de novas unidades produtivas. Para os agentes do segmento a desvalorização do dólar é o maior problema para o mercado de celulose e papel.

O sinal negativo do preço de exportação do papel pode está associado ao fato de o Brasil exportar papel e proceder com a importação, tendo em vista que o preço do papel importado é mais baixo, já que é subsidiado quando para produção de livros (papel imune).

As funções de impulso-resposta, resultantes da estimação do modelo VEC, demonstram os efeitos sobre as exportações brasileiras de papel resultantes de choques nas variáveis do modelo para os primeiros dez meses seguintes.

A Figura 2 indica as variações que cada uma das variáveis do modelo possui e os seus efeitos ao longo do período. Percebe-se que as variações causam maior efeito nos primeiros meses seguintes e que as séries passam a se estabilizar a partir do oitavo mês. 
Figura 2 - Função de impulso resposta das variáveis estimadas no modelo.

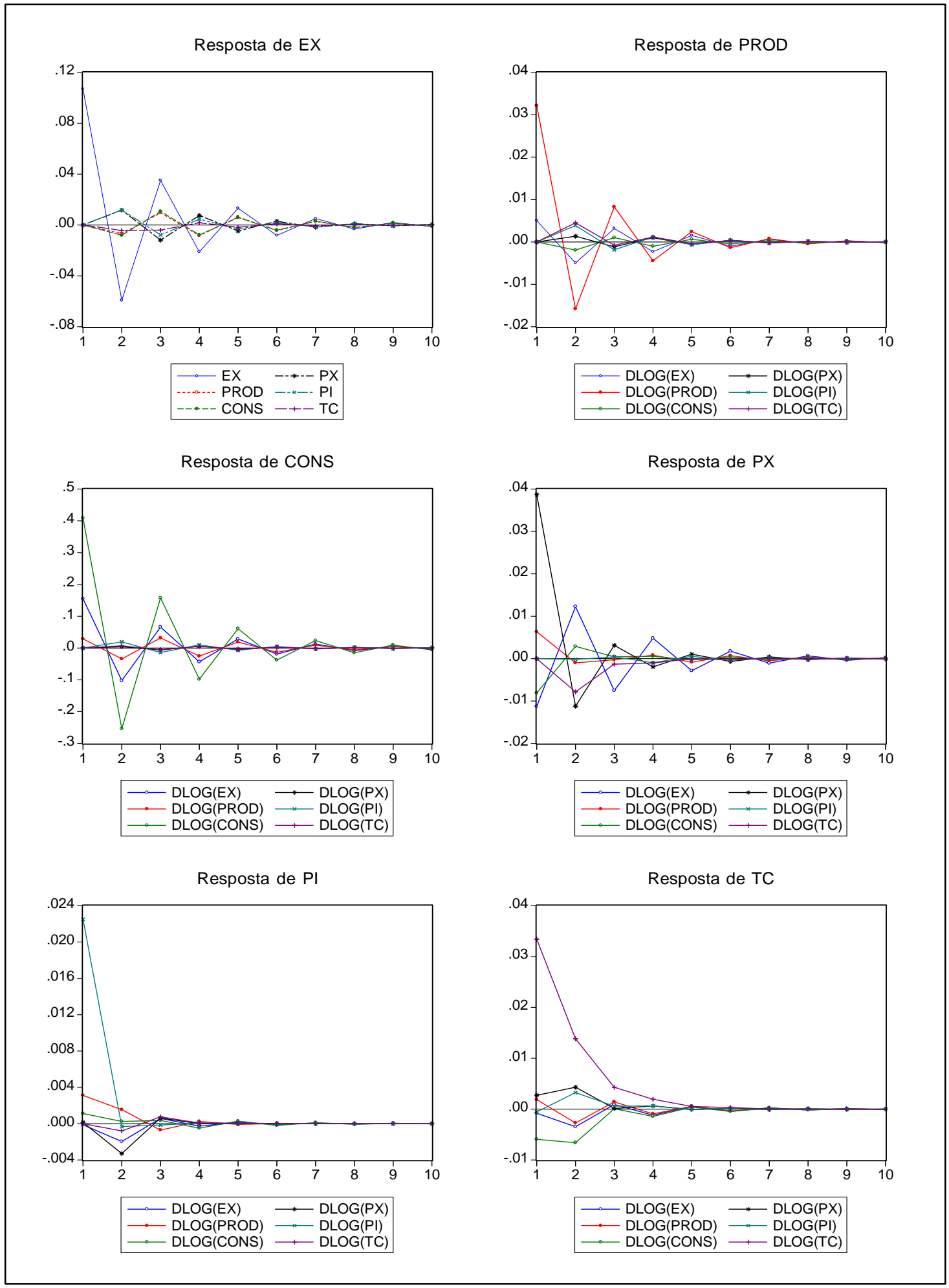

Fonte: Dados da Pesquisa. 
A função de impulso-resposta frente aos choques na produção nacional mostraramse expressivos no segundo e terceiro mês. O maior impacto ocorreu no segundo mês, ou seja, um aumento de $1 \%$ na produção nacional de papel contribui para uma redução de 0,05\% nas exportações no segundo mês. No terceiro mês, um aumento de $1 \%$ na produção nacional de papel contribui para um aumento de 0,03\% nas exportações (Figura 2).

O consumo nacional de papel tem um efeito positivo sobre as exportações do segundo ao quarto mês, sendo que o maior impacto acorre no segundo mês. Nesse período, um aumento de $1 \%$ no consumo nacional de papel contribui para um aumento $0,13 \%$ na quantidade exportada de papel pelo Brasil (Figura 2).

Com relação ao preço interno, o maior efeito acontece no décimo mês, isto é, um acréscimo de $1 \%$ no preço interno tende a aumentar as exportações em $0,08 \%$ nesse período (Figura 2).

Verificou-se que o efeito de uma variação na taxa de câmbio sobre a quantidade exportada de papel é maior no primeiro mês após o choque. Em outras palavras, um aumento de $1 \%$ taxa de câmbio provoca, após um ano, uma variação em sentido contrário nas exportações brasileiras de celulose da ordem de 0,17\% (Figura 2).

As funções de impulso-resposta analisadas demonstraram que, para uma mesma variação, há maior influência das variáveis produção e consumo aparente interno sobre o quantum exportado de papel. Além disso, observou-se que as variações no consumo de papel, produção, preço e taxa de câmbio tendem a se dissipar com certa rapidez, pois após 6 meses do choque inicial, as mesmas começam a retornar ao seu estado de equilíbrio.

A decomposição da variância do erro de previsão indicou que a produção de papel no Brasil responde por $0,64 \%$ das exportações no segundo mês, o consumo $0,1 \%$, o preço de exportação $2,1 \%$, o preço interno $1,1 \%$ e a taxa de câmbio $0,14 \%$. Raciocínio análogo para os demais períodos. Observa-se que a produção explica 0,64\% a 0,88 \% da variância do erro de previsão. O consumo explica de $0,018 \%$ a 6,8\% da variância do erro de previsão das exportações e o preço interno explica de $1,12 \%$ a $4,3 \%$, ao longo do período analisado. A taxa de câmbio e o preço de exportação explicaram em média 3,3\% e 2\% das exportações nacionais de papel, respectivamente, durante o período de dez meses e a produção, apresenta reduzido poder explicativo para essa variável (Tabela 5). 
Tabela 5 - Decomposição da variância dos erros de previsão

\begin{tabular}{cccccccc}
\hline Meses & $\begin{array}{c}\text { Desvio } \\
\text { padrão }\end{array}$ & Ex & Prod & Cons & Px & Pi & TC \\
\hline 1 & 0.102322 & 100.0000 & 0.000000 & 0.000000 & 0.000000 & 0.000000 & 0.000000 \\
2 & 0.123657 & 95.96033 & 0.640523 & 0.018231 & 2.114516 & 1.122660 & 0.143743 \\
3 & 0.133696 & 88.20633 & 0.629087 & 2.584567 & 1.820121 & 3.490389 & 3.269510 \\
4 & 0.136309 & 85.55824 & 0.640600 & 4.572984 & 1.911684 & 4.008057 & 3.308432 \\
5 & 0.137846 & 83.66432 & 0.789166 & 5.983134 & 1.932275 & 4.307941 & 3.323168 \\
6 & 0.138373 & 83.06543 & 0.858924 & 6.507216 & 1.934315 & 4.328600 & 3.305518 \\
7 & 0.138561 & 82.87788 & 0.879582 & 6.688084 & 1.930243 & 4.324133 & 3.300082 \\
8 & 0.138607 & 82.83970 & 0.881758 & 6.719990 & 1.929041 & 4.321679 & 3.307833 \\
9 & 0.138616 & 82.83352 & 0.881690 & 6.723169 & 1.929802 & 4.322214 & 3.309608 \\
10 & 0.138618 & 82.83097 & 0.881841 & 6.722958 & 1.930605 & 4.323214 & 3.310414 \\
\hline
\end{tabular}

Fonte: Dados da pesquisa

Pelos resultados do teste ADF nos resíduos do modelo VEC rejeitou-se a hipótese nula de raiz unitária, pois os valores críticos são menores, em módulo, que o $\tau_{\text {calculado }}$ (Tabela 6). Assim, os resíduos apresentaram comportamento tipo ruído branco.

Assim, o modelo foi satisfatório para a estimação realizada.

Tabela 6 - Teste de raiz unitária, em nível, para a série dos resíduos do modelo VEC

\begin{tabular}{cc}
\hline Modelo & Valores Calculados de ADF \\
\hline modelo I & $-12,79$ \\
modelo II & $-12,83$ \\
modelo III & $-12,87$ \\
\hline
\end{tabular}

Fonte: Dados da pesquisa. Nota: Valores críticos em nível de 1\%. Valores calculados de ADF em nível de $1 \%$ : $-4,01 ;-3,47 ;-2,57$ para os modelos com constante e com tendência, sem constante e com tendência e sem constante e sem tendência, respectivamente.

\section{Conclusão}

O modelo econométrico estimado mostrou que as variáveis que mais influenciaram as exportações no período analisado foram consumo aparente do Brasil, taxa de câmbio e preço interno. $\mathrm{O}$ preço de exportação apresentou sinal contrário à teoria econômica e a produção nacional, foi não significativa. Assim, recomendam-se pesquisas futuras 
utilizando outras variáveis explicativas e uma amostra maior no sentido de verificar se o preço de exportação apresentará o mesmo comportamento.

A decomposição da variância demonstrou que o consumo nacional de papel explica a maior parte das exportações nacionais do produto, seguida por preço interno, taxa de câmbio, preço de exportação e produção.

A função de impulso-resposta evidencia que os efeitos das variáveis selecionadas no modelo ocorrem mais intensamente nos primeiros meses e que as exportações brasileiras de papel responderam mais a fatores internos que externos.

Esses aspectos devem ser considerados ao se avaliarem os impactos de políticas macroeconômicas, ao se planejarem políticas setoriais para o setor e ao se decidir sobre estratégias empresariais de expansão das indústrias no setor de celulose e papel no Brasil.

Para o futuro da indústria brasileira de papéis, questões como o baixo consumo per capita, as dificuldades e entraves logísticos e tributários, bem como o reduzido porte das empresas, precisam ser equacionadas para que a competitividade nacional aumente e os investimentos, enfim, ganhem expressividade. A indústria de papel e celulose, por sua vez, deve buscar mecanismos de fortalecer a posição competitiva alcançada, garantindo que projetos de expansão se concretizem. Ao mesmo tempo, o segmento deve se direcionar para inovações e práticas sustentáveis visando a garantia da sua rentabilidade e posicionamento no longo prazo.

\section{Referências}

ALVES, L. R. A.; BACCHI, M. R. P.; Oferta de Exportação de Açúcar do Brasil. RER, Rio de Janeiro, vol. 42, n. 01, p. 09-33, jan/mar 2004.

BARROS, G.S. de C.; BACCHI, M.R.P.; BURNQUIST, H.L. Estimação de equações de oferta de exportação de produtos agropecuários para o Brasil (1992/2000). Texto para Discussão, Brasília: IPEA, n.865, mar. 2002.

BENEVIDES, Maria V. 1964: um golpe de classe? (Sobre um livro de Rene Dreifuss). Lua Nova, n. 58, CEDEC, Centro de Estudos de Cultura Contemporânea, São Paulo, Brasil, 2003.

BRACELPA. Conjuntura Bracelpa. Mar/2014. Disponível em < http://bracelpa.org.br/ > Acesso em 04.abr.2014. 
BRACELPA. Dados do setor de papel. 2013. Disponível em <http://www.bracelpa.org.br > Acesso em 08.abril.2013. (a)

BUENO, R. L. S. Econometria de séries temporais. São Paulo, Cengage Learning, 2008. CAMEX - CÂMARA DE COMÉRCIO EXTERIOR. Programa especial de exportações

- PEE. Brasília, 1999. Disponível em: <http://
www.planalto.gov.br/CAMEX/programa.htm>. Acesso em: 23 fev. 2014.

CARVAlHO, K. H. A. de; COSTA , C. C. de M.; SOARES, N. S.; SILVA, M. L. da. Desempenho das exportações brasileiras de papel. Revista Scientia Forestalis. Piracicaba, v. 38, n. 86, p. 263-271, jun. 2010.

CEPEA - Centro de Estudos Avançados em Economia Aplicada. 2014. Disponível em $<$ http://www.cepea.esalq.usp.br/>

ENDERS, W. Applied Econometric Time Series. New York: John Wiley, 1995. 433p.

EVIEWS. User's Guide. Irvine: QMS, 2004. 978 p. (Versão 5.0).

FAE BUSINESS. O mercado de papel e celulose. Revista FAE BUSINESS, n.1, 2001.

FOOD AND AGRICULTURE ORGANIZATION - FAO. Disponível em:

$<$ http//:www.fao.org>. Acesso em 10/out/2013.

FURTADO, C. Formação Econômica do Brasil. Edição 34, São Paulo: Saraiva. 2007. $352 \mathrm{p}$.

GOMIDE, J. L. Situação atual e perspectivas futuras do setor de celulose e papel no Brasil. In: SIMPÓSIO BILATERAL BRASIL-FINLÂNDIA SOBRE ATUALIDADES FLORESTAIS, 1988, Curitiba. Anais... Curitiba: UFPRIBDF,1988. p. 296-302.

IPEA - Instituto de Pesquisa Econômica Aplicada. 2014. Disponível em www.ipea.gov.br

JOHANSEN, S. Statistical Analysis of Cointegration Vectors. Journal of Economic Dynamics and Control 12, 231-254. Reimpresso em: Engle; Granger, Long-run Economic Relationships, Readings in Cointegration, Oxford University Press, 1991.

JUVENAL, T. L., MATTOS, R. L. G. (dezembro, 2002). O setor de celulose e papel. In: BNDES. BNDES 50 anos: Histórias Setoriais.

KRUGMAN, P. R.; OBSTFELD, M. Economia Internacional: Teoria e Política.São Paulo: Pearson Addison Wesley, 2005, 6 $\mathrm{a}$ ed, 558 p.

MDIC - Ministério do Desenvolvimento, Indústria e Comércio Exterior. Disponível em < http://www.mdic.gov.br> Acesso em 17/12/2014.

NOGUEIRA, F. T. P.; AGUIAR, D. R. D.; LIMA, J. E. Integração Espacial no Mercado Brasileiro de Café Arábica. Nova Economia, Belo Horizonte, v. 15, n. 2, p. 91 - 112, maio - agosto de 2005. 
SILVA, M. A. P; BRAGA, M. J; CAMPOS, A. C. Determinantes da oferta de exportação de carne de frango no período de 1992 a 2007. In: XLVI Congresso Brasileiro de Economia e Sociologia Rural 46, 2008, Rio Branco. Anais... Rio Branco, SOBER, 2008, $\mathrm{n}^{\circ} 46$.

SILVA, C. R. L. da; CARVALHO, M. A. de. Taxa de câmbio e preços de commodities agrícolas. Informações Econômicas, São Paulo, v. 25, n.5, p.23-35, Maio 1995.

SILVA, Márcia A. de; et al. Oferta de Exportação de Carne de Frango do Brasil de 1992 a 2007. RESR, Piracicaba, SP, vol. 49, nº 01, p. 31-54, jan/mar 2011.

SOARES, N. S. Análise da competitividade e dos preços da celulose e da madeira de eucalipto no Brasil. Viçosa, 2010. Tese (Doutorado) - UFV

SOARES, N. S.; SILVA, M. L.; LIMA, J. E. de. Oferta de exportação da celulose brasileira. Revista de Política Agrícola. Brasília, ano 20, n.2, p. 52-65, 2011.

SOTO, B. F. A. Da indústria do papel ao complexo florestal no Brasil: o caminho do corporativismo tradicional ao neocorporativismo. Campinas, 1992. Tese (Doutorado) UNICAMP

ZAEYEN, A. Estrutura e desempenho do setor de papel e celulose no brasil. 1986. $99 \mathrm{f}$. Dissertação (Mestrado em Economia) - Universidade Federal do Rio de Janeiro, Rio de Janeiro, 1986.

Submetido em: 17/01/16

Aceito em: 26/04/16 